\title{
PARADOXOS EM FINANCCAS: TEORIA MODERNA VERSUS FINANÇAS COMPORTAMENTAIS
}

RESUMO

Este artigo aborda as finanças comportamentais, uma das inovações mais importantes e controversas em finanças, que confrontam o paradigma tradicionalmente aceito, baseado na moderna teoria financeira. Inicialmente realiza-se uma síntese de potenciais problemas de tomada de decisão, exemplificando-se alguns aspectos não racionais que constituem importantes paradoxos em finanças. Após uma discussão da teoria de prospecto, replicam-se numa amostra brasileira os experimentos seminais de Kahneman e Tversky. São discutidas diversas situações que violam premissas da teoria da utilidade esperada, base da teoria moderna de finanças. Os resultados empíricos mostram que se mantêm as evidências de diversos vieses de percepção em decisões, independentemente de aspectos relacionados com a evolução do mercado e com a cultura ou nacionalidade dos indivíduos. 0 distanciamento entre a teoria moderna de finanças e a prática em decisões financei ras sugere a abordagem das finanças comportamentais como uma al ternativa para explicar o comportamento dos agentes econômicos.

\section{Herbert Kimura}

Universidade Presbiteriana Mackenzie

\section{Leonardo Fernando Cruz Basso}

Universidade Presbiteriana Mackenzie

\section{Elizabeth Krauter}

FEA-USP

\begin{abstract}
This study discusses the Behavioral Finance, one of the most important and controversial innovations in finance, that confronts the traditionally accepted paradigm based on the M odern Finance Theory. Initially, a synthesis of potential problems of decision-making is carried through, with examples of some non-rational aspects that make up important paradoxes in finance. After a discussion of the prospect theory, the seminal experiments of Kahneman and Tversky are replicated in a Brazilian sample. Many situations that violate premises of the theory of the expected utility, base of the M odern Finance Theory, are presented. Empirical results show that evidences of many perception biases in decisionmaking are consistent, independently of aspects related with the evolution of the market and the culture or nationality of individuals. The separation between theory and practice in financial decisions suggests the Behavioral Finance as an alternative to explain attitudes of economic agents.
\end{abstract}

PALAVRAS-CHAVE Finanças comportamentais, comportamento do investidor, teoria moderna de finanças, teoria da utilidade esperada, vieses cognitivos.

KEYORDS Behavioral finance, investor behavior, modern finance theory, expected utility theory, cognitive biases. 


\section{INTRODUÇÃO}

As recentes e rápidas transformações socioeconômicas que envolvem o ambiente empresarial têm levado ao questionamento das teorias organizacionais. 0 distanciamento cada vez mai or entre o discurso e a prática constitui importante tema a ser investigado. Se por um lado os model os teóricos tradicionais possibilitam 0 direcionamento e o entendimento de diversas decisões empresariais, por outro lado, as discrepâncias entre as atitudes esperadas e os comportamentos efetivos instigam a busca de novas teorias.

Dentro do conceito de paradoxos, este estudo foca a atenção em uma das idéias centrais em pesquisas envolvendo teorias transformacionais: a racionalidade e a irracional idade simultâneas dos agentes organizacionais. N esse contexto, este estudo apresenta resultados que desafiam o modelo de racionalidade dos agentes financeiros em um contexto da hipótese de mercados eficientes (Fama, 1970), um dos pilares das finanças tradicionais, denominada teoria moderna de finanças.

A partir da aplicação do estudo seminal desenvolvido por Kahneman e Tversky (1979) para o ambiente brasileiro, identifica-se que a decisão efetiva dos indivíduos muitas vezes não é consistente com a decisão esperada a partir do modelo teórico de maximização da utilidade esperada. De fato, Daniel Kahneman e Amos Tversky são considerados os originadores de uma teoria alternativa, a Prospect Theory, que fundamenta as finanças comportamentais e confronta o paradigma da teoria financeira tradicional.

Este artigo também busca prestar uma homenagem aos pioneiros da teoria de finanças comportamentais, uma das inovações mais importantes e controversas em finanças, que concedeu a um de seus ideal izadores, Daniel Kanheman, o Prêmio Nobel de Economia de 2002. Deve-se destacar que Kahneman dividiu o Prêmio Nobel com Vernon Smith, que, por sua vez, elaborou experiências em laboratório que se tornaram ferramentas valiosas para a análise econômica empírica. É conveniente citar que Amos Tversky, co-autor da Prospect Theory, já havia falecido em 2002 e, portanto, não foi laureado, uma vez que o Prêmio N obel não é dado postumamente.

N este estudo, inicialmente, realiza-se uma síntese de experiências em psicologia que ilustram potenciais problemas de tomada de decisão, exemplificando-se al guns aspectos não racionais que podem influenciar as escolhas dos indivíduos. Esses aspectos comportamentais constituem importantes paradoxos, eviden- ciando um distanciamento entre teoria e prática. A presenta-se também uma breve discussão da teoria de prospecto, que fundamenta as finanças comportamentais. Final mente, realiza-se a replicação em uma amostra brasileira dos experimentos seminais de Kahneman e Tversky (1979) direcionados mais especificamente para decisões financeiras. Evidenciam-se as situações que violam a teoria da utilidade esperada, base de diversos teoremas da hipótese de mercados eficientes. Confrontam-se os resultados obtidos na amostra de brasileiros com os obtidos na amostra dos indivíduos contemplados nos trabalhos originais de Kahneman e Tversky.

\section{REFERENCIAL TEÓRICO}

Com a atribuição do Prêmio Nobel de Economia de 2002 a Daniel Kahneman, as finanças comportamentais se estabeleceram como uma teoria que desafia o paradigma imposto pela hipótese de mercados eficientes. Considerando que as decisões financeiras podem ser influenciadas por processos mentais, os defensores das finanças comportamentais argumentam que atitudes não racionais dos agentes econômicos podem impactar, de maneira prolongada e consistente, o comportamento de variáveis financeiras.

De acordo com Shefrin (2000), as finanças comportamentais correspondem a uma área do conhecimento que vem apresentando grande crescimento, preocupando-se com o estudo da influência da psicologia no comportamento dos agentes do mercado financeiro. Enquanto a teoria moderna de finanças é baseada na busca da maximização da utilidade esperada, as finanças comportamentais estabelecem que al gumas variáveis econômicas não podem ser descritas pelas condições de equilíbrio da teoria moderna, tendo em vista que os agentes financeiros tomam decisões muitas vezes incompatíveis com atitudes baseadas em expectativas racionais.

Fundamentadas nos trabalhos seminais de Kahneman e Tversky (1979), as finanças comportamentais foram alvo de fortes críticas, cuja argumentação se apoiava na hipótese de mercados eficientes, proposição central de finanças por mais de 30 anos. Após sua concepção, na década de 1960, a hipótese de mercados eficientes apresentou um enorme sucesso, tanto teórica quanto empiricamente. Ao mesmo tempo em que os acadêmicos desenvolviam razões teóricas para a validade da hipótese (Shleifer, 2000), diversas descobertas empíricas corroboravam os avanços teóricos. Jensen (1978) chegou a declarar que nenhuma 
outra proposição em economia possuía evidência empírica mais sólida do que a hipótese de mercados eficientes.

Entretanto, mais recentemente, diversos estudos têm desafiado os fundamentos teóricos e os resul tados práticos da hipótese de mercados eficientes. Várias anomalias de mercado em relação aos resultados esperados por meio da hipótese de mercados eficientes foram identificadas, e não foram adequadamente explicadas pela teoria moderna de finanças.

Thaler (1999) discute cinco enigmas em que o comportamento no mundo real parece entrar em conflito com a teoria tradicional de finanças, sugerindo, portanto, campos de estudo para as finanças comportamentais. Os cinco enigmas são os seguintes:

- volume: os modelos tradicionais de mercado de capitais predizem que deveria haver poucas transações, pois em um mundo no qual os operadores são racionais seria pouco provável que os agentes financeiros comprassem e vendessem ações. De Bondt e Thaler (1985) afirmam que o excesso de confiança dos gestores de carteira e a relação de agência podem ser razões para este enigma do volume negociado. Comportamentalmente, o excesso de confiança implicaria a sensação, por parte dos gestores, de possibilidade de obteção de retornos ajustados por riscos maiores do que os da carteira de mercado;

- volatilidade: em um mundo onde as pessoas são racionais, somente ocorreriam alterações de preço quando surgisse nova informação rel evante. Porém, o comportamento do mercado tem demonstrado que os preços parecem apresentar muito mais flutuação do que seria de esperar somente por al terações nos valores presentes dos dividendos futuros. Cutler, Poterba e Summers (1989) examinam a possibilidade de o mercado se mover em função da evolução do consenso sobre conseqüências de novas informações e em função dos mecanismos de propagação de informação. N este modelo, pequenas alterações em taxas de desconto ou em fluxos de caixa projetados poderiam causar grandes efeitos em preços, gerando situações de grande volatilidade e até mesmo pânico dos participantes do mercado financeiro;

- dividendos: tendo em vista que na legislação americana os dividendos são tributados com uma alíquota maior do que os ganhos de capital, não seria racional as empresas distribuírem dividendos a curto prazo aos acionistas. Porém, a prática do mercado tem mostrado que não somente as empresas distribuem os dividendos como também o seu aumento leva a uma valorização das ações. Essa evidência pode estar associada a um viés cognitivo denominado, dentro de um contexto de estruturação, contabilização mental. Nesse caso, os dividendos podem ser percebidos como um valor adicional à renda, enquanto os ganhos de capital não implicam diretamente recebimento de caixa (Barberis e Huang, 2001);

- prêmio das ações: historicamente, os retornos de longo prazo em investimento em ações têm sido muito maiores do que os retornos de longo prazo de títulos sem risco. Essa diferença não pode ser explicada somente por meio do diferencial de risco. Bernartzi e Thaler (1995) levantam uma possível explicação para essa anomalia baseada em um viés cognitivo. A miopia da aversão às perdas estabelece que a análise de horizontes temporais mais longos torna, segundo a percepção do investidor, um investimento arriscado mais atraente. Em contrapartida, ao avaliar uma carteira em horizontes mais curtos, como, por exemplo, um ano, os investidores percebem um portfólio arriscado como tendo um risco ainda maior, exigindo maiores taxas de retornos. Assim, existe uma miopia na percepção de possíveis perdas da carteira, em função de uma avaliação viesada do risco;

- previsibilidade: embora a hipótese de mercados eficientes estabel eça que não se podem prever retornos futuros dos ativos a partir da informação existente, cada vez mais as evidências têm mostrado que os preços dos ativos são pelo menos parcialmente previsíveis com base em retornos passados ou dados fundamentalistas. Em particular, essa anomalia pode ser explicada por reações anormais de preço devido ao comportamento dos indivíduos. Segundo De Bondt e Thaler (1985), o excesso de confiança poderia estar associado à sobre-reação de preços, fazendo com que a informação, positiva ou negativa, sobre um investimentimento tenha sua influência alavancada. Em contrapartida, o conservadorismo poderia estar associado à sub-reação de preços, uma vez que os investidores ajustariam lentamente suas avaliações a novas informações relevantes. Esses comportamentos dos participantes do mercado fazem com que parte do retorno de um ativo possa estar dissociada do risco, violando a hipótese de mercados eficientes.

Paralelamente às tentativas de explicação dessas anomalias por meio de considerações baseadas na hipótese de mercados eficientes, as finanças comportamentais surgem como uma forma al ternativa de avaliação dos movimentos de mercado. Segundo as finanças com- 
portamentais, não se deve esperar que o mercado seja eficiente. Pelo contrário, em função de aspectos comportamentais e de processos de tomada de decisão que não seguem a regra da utilidade esperada, deve-se esperar a existência e a persistência de desvios significantes e sistemáticos em relação aos valores esperados em mercados eficientes (Shleifer, 2000).

Thaler (1999) prediz que o termo finanças comportamentais, apesar de ainda representar uma teoria em desenvolvimento, em um futuro próximo será tratado como uma redundância, pois cada vez mais o comportamento dos indivíduos será incorporado aos modelos financeiros.

\section{Aspectos comportamentais}

o comportamento humano é influenciado por diversos aspectos psicológicos que podem distorcer a identificação e a percepção dos fatos. Isso leva a uma decisão baseada em julgamentos individuais, nos quais a racionalidade imposta pela teoria da utilidade esperada pode não ser obedecida. A seguir são apresentados alguns aspectos comportamentais que podem afetar 0 processo de tomada de decisão e os possíveis impactos em investimentos financeiros. Alguns vieses cognitivos comentados anteriormente, tais como contabilização mental, excesso de confiança e miopia de aversão a perdas, têm rel ação com os aspectos comportamentais discutidos a seguir.

\section{Dissonância cognitiva}

Em função da percepção seletiva, Festinger (1957) desenvolveu uma teoria na qual propõe que os indivíduos tentam, na medida do possível, reduzir a dissonância cognitiva. Um dos estudos mais famosos em toda a história da psicologia social foi realizado por Festinger e Carlsmith (1959) com estudantes recrutados para executar uma atividade muito entediante. Simplificadamente, descartando o grupo de controle, havia dois grupos distintos de estudantes: para cada membro do primeiro grupo a tarefa entediante renderia $\$ 1,00$; para os membros do segundo grupo a mesma tarefa renderia $\$ 20,00$. Ao final da execução da tarefa, os indivíduos teriam que dizer para um outro indivíduo que a tarefa que haviam acabado de real izar tinha sido muito agradável. A pós isso, os pesquisadores pediam para cada estudante avaliar, segundo sua percepção individual, como realmente havia sido a tarefa em termos de tédio ou agradabilidade.

0 resultado da pesquisa mostrou que o grupo composto pelos indivíduos que receberam apenas $\$ 1,00$ pela tarefa achava a atividade executada mais agradá- vel do que o grupo dos indivíduos que haviam recebido $\$ 20,00$ pela mesma tarefa. Os pesquisadores argumentaram que o grupo que havia ganhado pouco pela tarefa apresentava uma al ta dissonância cognitiva. 0 valor de \$1,00 recebido, muito baixo, destoava da lógica de se realizar uma tarefa entediante e mais ainda de se propagar que a tarefa havia sido agradável. Para diminuir essa dissonância entre atitude e percepção, esses indivíduos, talvez sem perceber, ajustavam sua opinião sobre a tarefa, numa tentativa de justificar sua própria atitude.

As atitudes dos investidores também podem ser influenciadas pelas tentativas de diminuição de sua dissonância cognitiva. Suponha um investidor que comprou uma determinada ação em função de uma expectativa de al ta extraordinária do preço dessa ação. No caso de queda acentuada do preço da ação, o resultado financeiro para o indivíduo pode ser encarado como uma perda pouco considerável, como forma de justificar a aquisição da ação e diminuir a importância do prejuízo incorrido. Esse fato pode estar associado à evidência empírica de os indivíduos postergarem a realização de prejuízos (O dean, 1998) .

\section{Inconsistência}

A inconsistência depende da identificação de incoerência entre atitudes. Por exemplo, Prothro e Grigg (1960) conduziram um estudo em que alguns princípios democráticos eram el encados e aceitos pel os participantes da pesquisa. A seguir, os autores perguntavam aos mesmos participantes sobre sua concordância ou discordância em relação a algumas frases que contradiziam os princípios anteriormente aceitos. U ma grande parcela dos participantes, apesar de terem definitivamente aceitado os princípios de democracia apresentados inicial mente, demonstraram grande concordância com frases eminentemente antidemocráticas.

Outro levantamento extremamente rel evante sobre inconsistências ou discrepâncias entre atitude e comportamento foi realizado por Wicker (1969). Por meio da análise de diversos estudos sobre atitudes e comportamentos correspondentes, Wicker concluiu que a probabilidade de que as atitudes não se correl acionem ou se correlacionem pouco com comportamentos manifestos é maior do que a probabilidade de haver alta correl ação entre atitudes e comportamentos efetivos.

U ma inconsistência tradicional mente encontrada no mercado financeiro se refere à diversificação. Apesar de a diversificação ser aclamada pelos investidores como um princípio adequado a ser seguido, King e 
Leape (1998) observaram que o número médio de ações que fazem parte da carteira dos indivíduos é insuficiente para uma adequada mitigação de riscos.

\section{Ancoragem e conservadorismo}

Edwards (1954) propõe um problema baseado em probabilidades que demonstram que os indivíduos em geral têm um valor de referência que ancora suas percepções, levando-os a estimativas conservadoras. N esse estudo, Edwards estabelece 100 sacolas, cada uma contendo 1.000 objetos. Cada uma das primeiras 45 sacolas contém 700 objetos pretos e 300 objetos vermeIhos. Em cada uma das 55 sacolas restantes há 300 objetos pretos e 700 objetos vermel hos. Na primeira questão proposta, pergunta-se qual a probabilidade de se sel ecionar uma sacola que contenha predominantemente objetos pretos. $\mathrm{Na}$ segunda questão, são retirados 12 objetos, com reposição, da sacola selecionada na primeira questão. Sendo oito pretos e quatro vermelhos, pede-se para o indivíduo estimar a probabilidade de a sacola sel ecionada conter mais objetos pretos. A primeira questão, em geral, é respondida de manei ra correta: $45 \%$. Na segunda questão, porém, as estimativas mais comuns são $45 \%$ e $67 \%$, ambas menores do que o valor correto, utilizando a teoria das probabilidades, que é de aproximadamente $96 \%$. 0 estudo mostra, portanto, que os indivíduos consideram a informação adicional de forma inadequada, 0 que os leva a estimativas conservadoras.

Shefrin (2000) afirma que a deficiência do indivíduo em analisar a informação adicional no caso acima é análoga à deficiência que os analistas financeiros apresentam quan do fazem novas estimativas sobre lucros futuros de uma empresa, em função do surgimento de nova informação rel evante. Segundo o autor, devido ao conservadorismo, os anal istas não revisam suficientemente suas estimativas para refl etir novas informações. Dessa maneira, informações positivas sobre lucros inesperados tendem a ser seguidas por novos lucros inesperados. De modo análogo, informações negativas inesperadas são comumente seguidas por novas perdas não previstas.

\section{Arrependimento}

Segundo Loomes e Sugden (1982), o arrependimento fundamenta-se em duas premissas. A primeira estabelece que as pessoas passam por experiências que as conduzem a uma sensação de arrependimento. A segunda afirma que, quando as pessoas tomam decisões em condições de incerteza, tentam antecipar prová- veis sensações de arrependimento, levando-as em consideração no processo decisório.

Com relação ao mercado financeiro, Benartzi e Thaler (1995) apresentam uma regra genérica seguida por muitas pessoas, baseada na alocação aproximadamente igualitária de recursos entre os vários ativos. As pessoas tendem, por exemplo, em processos de investimento para aposentadoria, a investir $50 \%$ em ativos de renda variável e $50 \%$ em ativos de renda fixa. Se o mercado acionário apresentar uma alta considerável, essas pessoas terão uma sensação de arrependimento pequena, pois, pelo menos estarão obtendo parte da alta das ações. Se o mercado acionário apresentar uma queda considerável, 0 arrependimento também será amenizado, tendo em vista que parte dos recursos terá sido protegida em investimentos de renda fixa.

\section{Teoria de prospecto}

A teoria da utilidade esperada tem dominado a análise de decisões sob condições de incerteza (Kahneman e Tversky, 1979). Mais ainda, em termos de teoria moderna de finanças, a suposição da hipótese de eficiência de mercado implica que, em geral, os agentes econômicos tomem decisões racionais seguindo a utilidade esperada. Porém, diversos experimentos mostram que a racionalidade esperada por meio da teoria da utilidade nem sempre é verificada na prática. N esse contexto, a teoria de prospecto surge como uma al ternativa sobre as escolhas dos indivíduos, representando uma forte crítica à teoria da utilidade esperada como ferramenta de descrição do processo de tomada de decisão.

Segundo a teoria de prospecto, em vez de se atribuírem val ores aos resultados finais, el es são atribuídos aos ganhos e às perdas, e as probabilidades são substituídas por pesos ou ponderação na decisão (Kahneman e T versky, 1979). U m prospecto ou jogo representado por $\left(x_{1}: p_{1} ; \ldots ; x_{n}: p_{n}\right)$ corresponde a um contrato que leva ao resultado $x_{i}$ com probabilidade $p_{i}$, onde $p_{1}+\ldots+p_{n}=1$.

Para a teoria de prospecto, existem duas fases no processo de escolha: fase de edição e fase de avaliação. A fase de edição consiste em uma análise preliminar de possíveis prospectos, que conduz a uma simplificação da representação desses prospectos. A função dessa fase é organizar e reformular as alternativas de modo a simplificar as escolhas. A fase de edição foi posteriormente transformada, por Kahneman e Tversky (1981), no conceito de estruturação, cujos efeitos podem impor grandes obstáculos às teorias normativas para a tomada de decisão.

$\mathrm{Na}$ fase de avaliação, são avaliados os prospectos 
editados e é escolhido o prospecto de maior valor. De acordo com Kahneman e Tversky (1979), o valor V de cada prospecto é expresso em termos de duas escalas, denotadas por $\pi$ e $v$. A escala $\pi$ associa cada probabilidade $p$ a um peso de decisão $\pi(p)$ que refl ete $o$ impacto de $p$ no valor total do prospecto. Porém, $\pi$ não corresponde a uma medida de probabilidade, e na maioria dos casos $\pi(p)+\pi(1-p)<1$. Já a escala $n$ estabel ece, a cada resultado de ganho ou perda $x$, um número $v(x)$ que reflete um val or subjetivo de ganho ou perda em relação a um valor de referência. A função de valor possui as seguintes características: é definida a partir de um ponto de referência, e é côncava no domínio dos ganhos e convexa no domínio das perdas, sendo mais íngreme nas perdas do que nos ganhos. Já a função de ponderação $\pi$ relaciona os pesos de decisão às probabilidades de ocorrência ( $p$ ) dos resultados e possui as seguintes características (Kahneman e T versky, 1979): écrescente, $\operatorname{com} \pi(0)=0$ e $\pi(1)=1$; para pequenos valores de $p, p$ é uma função subaditiva de $p$, ou seja: $r . p$ > $r . \pi(p)$ para $0<r<1$; para probabilidades $p$ muito baixas, $\pi(p)>p$; e para todo $0<p<1, \pi(p)+\pi(1-p)<1$.

Destaca-se que, para uma proporção fixa entre probabilidades, a proporção correspondente aos pesos de decisão é mais próxima à unidade quando as probabilidades são baixas do que quando as probabilidades são al tas. Além disso, a função $p$ não é bem comportada nos pontos extremos, pois as pessoas têm habilidade limitada em avaliar probabilidades extremas: eventos al tamente improváveis são ignorados ou subvalo-

Figura 1 - Peso de decisão e função de valor.

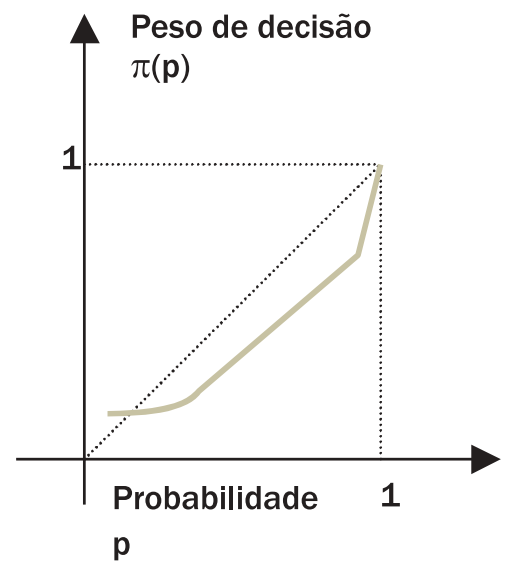

rizados, e a diferença entre eventos de alta probabilidade e eventos certos é negl igenciada ou exagerada. A seguir, são estilizados os formatos da função de ponderação e da função de valor, de acordo com as características definidas pela teoria de prospecto.

\section{MÉTODO DA PESQUISA EMPÍRICA}

Seguindo a metodologia proposta por Kahneman e Tversky (1979), foram levantadas, junto a uma amostra de respondentes, as escolhas individuais perante al ternativas envolven do condições hipotéticas de certeza ou de incerteza. Os prospectos a serem comparados foram idênticos aos da pesquisa de Kahneman e Tversky, variando-se somente a moeda considerada. Enquanto a pesquisa original supunha uma conversão para a moeda de Israel, a pesquisa desenvolvida neste artigo relacionou resultados em moeda do Brasil.

Por meio dos prospectos, analisam-se especialmente 0 efeito da certeza, o efeito da reflexão, o efeito da estruturação e a atitude perante 0 risco, que podem conduzir a uma série de vieses cognitivos em investimentos financeiros. Os valores dos prospectos originais se situavam em um patamar compatível com a renda mensal de uma família israelense. A pesar da diferença temporal de quase 25 anos entre esta pesquisa e a de Kahneman e Tversly, optou-se pelo uso dos mesmos prospectos. Como os valores originais têm a mesma ordem de grandeza da renda mensal de famílias

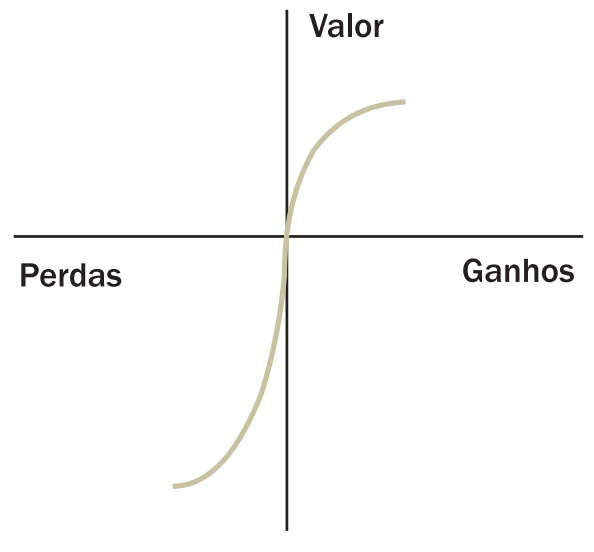

Fonte: Adaptado de Kahneman e Tversky (1979).

46 - ORAE - VOL. $46 \cdot \mathrm{N} N 1$ 
brasileiras de classe média, considerou-se que a opção pela manutenção dos mesmos montantes não prejudicaria as comparações entre as evidências do Brasil e de Israel. Os questionários foram distribuídos aos respondentes no primeiro semestre de 2003.

Ainda mantendo fidelidade ao trabalho original, buscou-se investigar o processo decisório de uma amostra de respondentes formada por alunos e professores universitários. Enquanto o estudo de Kahneman e Tversky apresentou resultados baseados em amostras compostas por estudantes e professores de escolas de Israel ou dos Estados U nidos, nesta pesquisa a amostra é composta por membros discentes e docentes de uma importante escola de negócios brasileira. 0 número de respostas levantadas nesta pesquisa é também semel hante ao do estudo original, e está evidenciado nos valores entre parênteses nas tabelas. Por exemplo, na Tabela 1, 98 indivíduos responderam o questionário em português, em comparação com 72 indivíduos na pesquisa original de Kanheman e T versky. 0 número de respostas consideradas para cada análise variou entre os prospectos, conforme pode se observar nas diferentes tabelas. Em média, o número de alunos representava $86 \%$ da amostra, enquanto 0 número de professores, $14 \%$. N ão se observou diferença significativa entre as respostas desses dois grupos de respondentes, mesmo havendo um potencial viés de al guns professores poderem estar familiarizados com a teoria de prospecto. Com relação à comparação entre porcentagens de al ternativas escolhidas, realizouse um teste de qui-quadrado. $N$ as tabelas, resultados com um asterisco são significativos ao nível de $1 \%$.

Por meio do questionário, o respondente deveria comparar os prospectos dois a dois. Para diminuir os problemas associados a potenciais efeitos da ordem das alternativas nas decisões a serem tomadas, os prospectos foram apresentados em ordem distinta para diferentes respondentes. Para al guns respondentes, determinado prospecto era apresentado como primeira alternativa, já para outros, o mesmo prospecto era a última alternativa apresentada. Além disso, como parte das instruções para o preenchimento do questionário, mencionou-se explicitamente que não havia resposta correta, uma vez que as escolhas dependeriam de preferências pessoais.

É importante destacar que Kahneman e Tversky (1979) defendem a metodologia adotada a despeito de possíveis problemas com relação, principalmente, à validade do método e à generalização dos resultados devido ao uso de prospectos hipotéticos. Os autores argumentam que outras metodologias de investigação e teste da teoria da utilidade esperada têm diversas deficiências. A consideração de prospectos reais pode exigir, por um lado, a adoção de pesquisa de campo que conduza somente a resultados qualitativos devido à fal ta de mecanismos robustos para a mensuração da utilidade atribuída e à limitação do número de respondentes. Por outro lado, quando prospectos reais são avaliados em pesquisa em laboratório - apesar da possibilidade de realização de vários experimentos e da obtenção de resultados quantitativos mais expressivos e com significância estatística - , existe a inconveniência de 0 respondente ter uma postura de propensão a riscos. Isso porque, nessas circunstâncias, em que os resultados das alternativas devem ser efetivamente pagos ou recebidos, os valores em jogo são geralmente reduzidos.

Considerando que os indivíduos têm noção de suas preferências frente a decisões reais e que não têm motivos recorrentes para responder às situações hipotéticas de modo diferente das situações reais, para estudos em psicologia, pode-se justificar o uso de prospectos hipotéticos por permitirem um grande número de observações para uma grande variedade de problemas decisórios. Dessa maneira, este estudo parte da premissa de que as escolhas para as alternativas propostas no questionário refletem o processo decisório dos indivíduos em situações reais.

\section{RESULTADOS E DISCUSSÃO}

Conforme se apresentou no referencial teórico, vários processos mentais podem influenciar a tomada de decisão, fazendo com que a racionalidade imposta pela regra da utilidade esperada não seja obedecida. 0 paradoxo proposto por Allais (1953) é um exemplo clássico envolvendo decisões financeiras. Explorando o chamado efeito da certeza (certainty effect), o paradoxo estabelece que as preferências por prospectos podem depender não somente da utilidade atribuída aos resultados em si, mas também do nível de certeza dos prováveis resultados. Por meio do efeito da certeza, a escolha de prospectos pode violar o princípio de que os indivíduos ponderam as utilidades a partir das probabilidades de ocorrência de cada um dos possíveis resultados. 0 efeito da certeza pode ser avaliado por meio das respostas para os problemas definidos nas Figuras 2 e 3 . Ambas as figuras apresentam variantes do exemplo de Allais. 
$\mathrm{Na}$ Tabela 1 confrontam-se os resultados da escolha dos prospectos realizada pelos participantes da amostra brasileira com os resultados originais obtidos por Kahneman e Tversky (1979). Os números entre parênteses após a classificação entre "Brasil" e "Original" representam o número total de respondentes. Assim, nos Problemas 1 e 2, a amostra dos trabal hos originais era composta por 72 indivíduos, enquanto a amostra da pesquisa brasileira englobou 98. Ainda conforme o critério de apresentação dos resultados utilizado por Kahneman e Tversky, a presença de um asterisco após a freqüência de respostas em cada problema representa que a preferência pelo prospecto é significativa ao nível de $1 \%$, utilizando-se o teste do qui-quadrado.

Figura 2 - Enunciado do estudo do efeito da certeza.

Problema 1. Qual das duas alternativas você prefere?

( ) Alternativa A

$33 \%$ de chances de ganhar $\$ 2500$

$66 \%$ de chances de ganhar $\$ 2500$

$1 \%$ de chances de ganhar $\$ 0$

Problema 2. Qual das duas alternativas você prefere?

( ) Alternativa C

$33 \%$ de chances de ganhar $\$ 2500$

$67 \%$ de chances de ganhar $\$ 0$
( ) Alternativa B

$100 \%$ de chances de ganhar $\$ 2500$

Problema 3. Qual das duas alternativas você prefere?

( ) Alternativa A

$80 \%$ de chances de ganhar $\$ 4000$

$20 \%$ de chances de ganhar $\$ 0$

Problema 4. Qual das duas alternativas você prefere?

( ) Alternativa A

$20 \%$ de chances de ganhar $\$ 4000$

$80 \%$ de chances de ganhar $\$ 0$
( ) Alternativa D

$34 \%$ de chances de ganhar $\$ 2400$

$66 \%$ de chances de ganhar $\$ 0$

Problema 5. Qual das duas alternativas você prefere?

( ) Alternativa A

$50 \%$ de chances de ganhar uma viagem de três

semanas para a Inglaterra, França e Itália

$50 \%$ de chances de não ganhar nada

Problema 6. Qual das duas alternativas você prefere?

( ) Alternativa A

$5 \%$ de chances de ganhar uma viagem de três

semanas para a Inglaterra, França e Itália

95\% de chances de não ganhar nada
( ) Alternativa B

$100 \%$ de chances de ganhar $\$ 3000$
( ) Alternativa B

$25 \%$ de chances de ganhar $\$ 3000$

$75 \%$ de chances de ganhar $\$ 0$

Fonte: Adaptado de Kahneman e Tversky (1979). 
As freqüências de escolhas por prospectos apontam para uma violação da regra da utilidade esperada, havendo uma reversão da ordenação da utilidade. Assim, ao avaliar o Problema 1, se a maioria das pessoas escolhe o Prospecto $B$, então considerando $\mathrm{U}(0)=0$, tem-se, por meio da regra da utilidade esperada, que $\mathrm{U}(2400)>0,33 \mathrm{U}(2500)+0,66 \mathrm{U}(2400) \Rightarrow$ $0,33 \cup(2500)<0,34 U(2400)$. Por outro lado, ao preferir o Prospecto $C$ no Problema 2, a maioria dos respondentes estabelece implicitamente o oposto, ou seja, 0,33U (2500) >0,34U (2400). Esse comportamento médio reflete inconsistência, pois não seria razoável, por meio da teoria da utilidade esperada, uma alteração na ordem de preferência entre resultados. Deve se notar que o Problema 2 foi obtido do Problema 1 ao eliminar-se a chance de ganhar $\$ 2.400 \mathrm{em}$ ambos os prospectos com uma probabilidade de $66 \%$.

Os dados da amostra brasileira, porém, conduzem a resultados menos significativos que os resultados da amostra original. Em particular, enquanto a amostra original apresentava preferências significativas para os Problemas 1 e 2, suportando o paradoxo de Allais, a amostra brasileira não permite a mesma avaliação do ponto de vista de significância estatística. Entretanto, quando são analisadas simultaneamente as escolhas de cada indivíduo frente aos dois problemas, observa-se que, tanto na amostra original quanto na amostra brasileira, diversos indivíduos tomam decisões que revertem a utilidade relativa dos resultados estritamente positivos. Constatou-se que $39 \%$ dos respondentes da pesquisa realizada no Brasil preferem o Prospecto $B$ do Problema 1 e o Prospecto $C$ do Problema 2, ou 0 Prospecto A do Problema 1 e o Prospecto D do Problema 2, evidenciando a incoerência das relevâncias relativas atribuídas às utilidades.

Os resultados obtidos na pesquisa sugerem que uma parcela considerável da população pode violar a regra da utilidade esperada na tomada de decisão financeira. Dessa maneira, modelos baseados na ponderação das utilidades pelas probabilidades de ocorrências de resultados podem ser pouco representativos do processo real de avaliação de al ternativas. 0 resultado não se al tera quando os problemas envolvem apostas com apenas dois resultados. Esta última afirmação é corroborada pelos resultados dos Problemas 3 e 4, apresentados na Tabela 1.

Novamente, apesar de não haver na amostra brasileira diferenças significativas nas freqüências de escoIhas de prospectos para ambos os problemas, a análise das respostas individuais é marcante: cerca de $60 \%$ dos respondentes tomam decisões que não seguem a regra

Tabela 1 - Estudo do efeito da certeza

\begin{tabular}{|c|c|c|c|}
\hline PROBLEMA & $\begin{array}{l}\text { PROSPECTO } \\
\end{array}$ & BRASIL (98) & ORIGINAL (72) \\
\hline 1 & $\begin{array}{l}\text { A: }(\$ 2500: 33 \% ; \$ 2400: 66 \% ; \$ 0: 1 \%) \\
\text { B: }(\$ 2400: 100 \%)\end{array}$ & $\begin{array}{l}30 \% \\
70 \% *\end{array}$ & $\begin{array}{l}18 \% \\
82 \% *\end{array}$ \\
\hline PROBLEMA & PROSPECTO & BRASIL (98) & ORIGINAL (72) \\
\hline 2 & $\begin{array}{l}C:(\$ 2500: 33 \% ; \$ 0: 67 \%) \\
D:(\$ 2400: 34 \% ; \$ 0,66 \%)\end{array}$ & $\begin{array}{l}52 \% \\
48 \%\end{array}$ & $\begin{array}{l}83 \% * \\
17 \%\end{array}$ \\
\hline PROBLEMA & PROSPECTO & BRASIL (97) & ORIGINAL (95) \\
\hline 3 & $\begin{array}{l}A:(\$ 4000: 80 \% ; \$ 0: 20 \%) \\
B:(\$ 3000: 100 \%)\end{array}$ & $\begin{array}{l}29 \% \\
71 \% *\end{array}$ & $\begin{array}{l}20 \% \\
80 \% *\end{array}$ \\
\hline PROBLEMA & PROSPECTO & BRASIL (97) & ORIGINAL (95) \\
\hline 4 & $\begin{array}{l}\text { C: }(\$ 4000: 20 \% ; \$ 0: 80 \%) \\
D:(\$ 3000: 25 \% ; \$ 0: 75 \%)\end{array}$ & $\begin{array}{l}57 \% \\
43 \%\end{array}$ & $\begin{array}{l}65 \% * \\
35 \%\end{array}$ \\
\hline PROBLEMA & PROSPECTO & BRASIL (98) & ORIGINAL (72) \\
\hline 5 & $\begin{array}{l}\text { A: (Viagem de três semanas para a Inglaterra, França e Itália: } 50 \% \text {; Nada: } 50 \% \text { ) } \\
\text { B: (Viagem de uma semana para a Inglaterra: } 100 \% \text { ) }\end{array}$ & $\begin{array}{l}20 \% \\
80 \% *\end{array}$ & $\begin{array}{l}22 \% \\
78 \% *\end{array}$ \\
\hline PROBLEMA & PROSPECTO & BRASIL (98) & ORIGINAL (72) \\
\hline 6 & $\begin{array}{l}\text { C: (Viagem de três semanas para a Inglaterra, França e Itália: 5\%; Nada: 95\%) } \\
\text { D: (Viagem de uma semana para a Inglaterra: 10\%; Nada: 90\%) }\end{array}$ & $\begin{array}{l}49 \% \\
51 \%\end{array}$ & $\begin{array}{l}67 \% * \\
33 \%\end{array}$ \\
\hline
\end{tabular}


da utilidade esperada. Assim, a maioria das pessoas prefere o conjunto de decisões formado pelo Prospecto $B$ do Problema 3 e pelo Prospecto $C$ do Problema 4, ou o conjunto formado pelo Prospecto $A$ do Problema 3 e o Prospecto $D$ do Problema 4. Os indivíduos que escolhem o primeiro conjunto de decisões estariam avaliando, por meio da teoria da utilidade esperada, que no Problema $3, U(3000)>0,8 U(4000)$, e no Problema $4, U(3000)>0,8 U(4000)$, configurando escoIhas inconsistentes. De modo análogo, as pessoas que escolhem o segundo conjunto também estão implicitamente tomando decisões inconsistentes.

Os resultados obtidos ilustram que 0 axioma da substituição não é respeitado por parcela representativa dos respondentes. Basta verificar que o Prospecto $C$ equivale ao Prospecto ( $A: 25 \%$ ) e o Prospecto $D$, ao Prospecto (B:25\%). Ou seja, a redução da probabilidade de ganho de $100 \%$ para $100 \%$. $25 \%=25 \%$ quando se considera os Prospectos A e C sensibiliza a percepção do indivíduo de maneira mais forte do que a redução da probabilidade de ganho de $80 \%$ para $80 \%$. $25 \%=20 \%$ quando são analisados os Prospectos B e D. Pelo axioma da substituição da utilidade esperada, se um Prospecto $X$ é preferível a outro Prospecto $Y$, então uma mistura dada por $(X: p)$ deve ser preferível a uma mistura dada por (Y:p). Problemas de violação ao axioma da substituição podem surgir também quando os resultados avaliados não são financeiros, conforme os Problemas 5 e 6 da Figura 2, cujos resultados estão descritos na Tabela 1.

Mais uma vez, a amostra brasileira está menos sujeita ao Paradoxo de Allais. Os resultados do Problema 5 evidenciam o efeito da certeza, tanto para o estudo original quanto para esta pesquisa. Assim, os indivíduos parecem preferir o certo ao incerto. No Proble- ma 6, a amostra brasileira não suporta diferenças significativas nas freqüências de escolha entre os Prospectos $C$ e D. Dessa maneira, não é possível, como no caso dos estudos originais, verificar que, quando as probabilidades de ganho são baixas, buscam-se resultados mais expressivos. Porém, quando se investigam situações de baixíssima probabilidade de ganho, evidencia-se a preferência por ganhos maiores, em detrimento da avaliação da probabilidade.

Considerem-se os dois prospectos da Figura 3. O bserve-se que no Problema 7 as probabilidades de ganho são substanciais ( $90 \%$ e $45 \%$ ) e a mai oria dos indivíduos escolhe o prospecto onde ganhar é mais provável. No Problema 8 existe a possibilidade de ganho, embora com probabilidades reduzidíssimas $(0,2 \%$ e $0,1 \%)$. Em situações como essas, ou seja, quando ganhar é possível, mas não provável, os indivíduos tendem a preferir os prospectos que oferecem ganhos maiores. A Tabela 2 descreve os resultados.

Tanto a amostra brasileira como a israelense mostram que, quando são avaliados prospectos com elevada probabilidade de ganho, os indivíduos tendem a escolher alternativas mais conservadoras no sentido de maior certeza de ganho. Assim, eles preferem, no Problema 7, o Prospecto B em detrimento do Prospecto A. Por outro lado, quando defrontados com situações de probabilidades muito baixas de ganho, os indivíduos ficam propensos a tentar obter ganhos maiores, mesmo que as probabilidades sejam menores, justificando a preferência pelo Prospecto $C$ em relação ao Prospecto D no Problema 8.

Assim, mais uma vez, observa-se que as atitudes dos indivíduos perante o risco não são adequadamente incorporadas pela teoria de utilidade esperada.

Figura 3 - Enunciado sobre atitudes perante o risco para diferentes probabilidades dos prospectos.

Problema 7. Qual das duas alternativas você prefere?

( ) Alternativa A

$45 \%$ de chances de ganhar $\$ 6000$

$55 \%$ de chances de ganhar $\$ 0$

Problema 8. Qual das duas alternativas você prefere?

( ) Alternativa A

$0,1 \%$ de chances de ganhar $\$ 6000$

$99,9 \%$ de chances de ganhar $\$ 0$
( ) Alternativa B

$90 \%$ de chances de ganhar $\$ 3000$

$10 \%$ de chances de ganhar $\$ 0$

( ) Alternativa B

$0,2 \%$ de chances de ganhar $\$ 3000$

$99,8 \%$ de chances de ganhar $\$ 0$

Fonte: Adaptado de Kahneman e Tversky (1979). 
Kahneman e Tversky (1979) propõem uma regra geral para a viol ação do axioma da substituição: se o prospecto (y:pq; 0:1-pq) é equivalente, em termos de preferência, ao prospecto ( $x: p ; 0: 1-p)$, então o prospecto (y:pqr; 0:1-pqr) é preferível ao prospecto (x:pr; 0:1$p r)$, onde $0<p, q, r<1$.

Nos problemas anteriores, foram avaliadas decisões perante prospectos positivos, ou seja, prospectos em que todos os possíveis cenários implicam ganho positivo ou nulo. Uma vez que ganhos ou perdas podem sensibilizar diferentemente o comportamento dos indivíduos, torna-se interessante investigar se os prospectos negativos, ou seja, os que implicam resultados negativos ou nulos, são avaliados de forma diferente.
Para contrapor os resultados, são apresentados 4 problemas na Figura 4.

A Tabela 3 mostra comparativamente as preferências entre prospectos positivos e negativos, evidenciando a existência do efeito de reflexão (reflection effect), ou seja, no domínio das perdas, o comportamento do indivíduo é de propensão a riscos, e no domínio dos ganhos, o comportamento é de aversão a riscos. É interessante observar que a amostra brasileira apresenta um número menor de situações em que o efeito de reflexão se manifesta de modo significativo, ao nível de $1 \%$. Porém, qual itativamente pode-se identificar que a decisão entre prospectos no domínio dos ganhos é diferente da decisão entre prospectos no domínio das perdas.

Tabela 2 - Atitudes perante o risco para diferentes probabilidades dos prospectos.

\begin{tabular}{|c|c|c|c|}
\hline PROBLEMA & PROSPECTO & BRASIL $(97)$ & ORIGINAL $(66)$ \\
\hline 7 & A: $(\$ 6000: 45 \% ; \$ 0: 55 \%)$ & $23 \%$ & $14 \%$ \\
& B: $(\$ 3000: 90 \% ; \$ 0: 10 \%)$ & $77 \% *$ & $86 \% *$ \\
\hline PROBLEMA & PROSPECTO & BRASIL $(97)$ & ORIGINAL $(66)$ \\
\hline 8 & C: $(\$ 6000: 0,1 \% ; \$ 0: 99,9 \%)$ & $72 \% *$ & $73 \% *$ \\
& D: $(\$ 3000: 0,2 \% ; \$ 0: 99,8 \%)$ & $28 \%$ & $27 \%$ \\
\hline
\end{tabular}

Figura 4 - Enunciado do estudo do efeito de reflexão em prospectos positivos e negativos.

Problema 3'. Qual das duas alternativas você prefere?

( ) Alternativa A

$80 \%$ de chances de perder $\$ 4000$

$20 \%$ de chances de perder $\$ 0$

Problema 4'. Qual das duas alternativas você prefere?

( ) Alternativa A

$20 \%$ de chances de perder $\$ 4000$

$80 \%$ de chances de perder $\$ 0$

Problema 7'. Qual das duas alternativas você prefere?

( ) Alternativa A

$45 \%$ de chances de perder $\$ 6000$

$55 \%$ de chances de perder $\$ 0$

Problema 8'. Qual das duas alternativas você prefere?

( ) Alternativa A

$0,1 \%$ de chances de perder $\$ 6000$

$99,9 \%$ de chances de perder $\$ 0$
( ) Alternativa B

$100 \%$ de chances de perder $\$ 3000$

( ) Alternativa B

$25 \%$ de chances de perder $\$ 3000$

$75 \%$ de chances de perder $\$ 0$

( ) Alternativa B

$90 \%$ de chances de perder $\$ 3000$

$10 \%$ de chances de ganhar $\$ 0$

( ) Alternativa B

$0,2 \%$ de chances de perder $\$ 3000$

$99,8 \%$ de chances de perder $\$ 0$

Fonte: Adaptado de Kahneman e Tversky (1979). 
Comparando as respostas dos Problemas 3 e 3', fica evidente que, tanto na amostra do trabalho original quanto na amostra brasileira, os indivíduos apresentam um comportamento de aversão ao risco no domínio dos ganhos e de propensão ao risco no domínio das perdas. Quando convidada a se decidir por um ganho certo de $\$ 3.000$ e uma probabilidade de $80 \%$ de ganhar $\$ 4.000$, a maioria dos indivíduos opta pelo ganho certo, denotando aversão ao risco. Entretanto, quando convidada a optar por uma perda certa de - $\$ 3.000$ e uma probabilidade de $80 \%$ de perda de - \$4.000, a maioria dos indivíduos opta pelo prospecto mais arriscado. Esse comportamento ajuda a compreender o nome dado por Kahneman e Tversky. A reflexão dos prospectos em torno do zero reverte a ordem de preferência, daí a expressão efeito de refl exão.

As preferências entre os prospectos negativos correspondentes também violam o princípio da expectativa (expectation principle), como se observou entre opções de prospectos com ganho. No domínio positivo, o efeito da certeza contribui para uma preferência pela aversão ao risco de um ganho certo sobre um ganho maior que é meramente provável. No domínio negativo, o mesmo efeito conduz a uma preferência pelo risco de uma perda provável sobre uma perda menor que é certa.

0 mesmo princípio psicológico, a sobrevalorização ( sobreponderação) da certeza (overweighting of certainty), favorece a aversão ao risco no domínio dos ganhos e a atração pelo risco no domínio das perdas. A busca de um ganho certo no Problema 3 e a tentativa de não obter prejuízo no Problema 3' sugerem que a aversão ao risco pode não apresentar comportamento único. Além disso, da mesma maneira que os Problemas 3 e 4, tampouco os Problemas 3' e 4' obedecem aos resultados da regra da utilidade esperada, sugerindo, mais uma vez, que resultados certos recebem um peso maior que re-

Tabela 3 - Estudo do efeito de reflexão em prospectos positivos e negativos.

\begin{tabular}{|c|c|c|c|}
\hline PROBLEMA & PROSPECTO & BRASIL (97) & ORIGINAL (95) \\
\hline 3 & $\begin{array}{l}A:(\$ 4000: 80 \% ; \$ 0: 20 \%) \\
B:(\$ 3000: 100 \%)\end{array}$ & $\begin{array}{l}29 \% \\
71 \% *\end{array}$ & $\begin{array}{l}20 \% \\
80 \% *\end{array}$ \\
\hline PROBLEMA & $\begin{array}{l}\text { PROSPECTO } \\
\text { PRE }\end{array}$ & BRASIL (97) & ORIGINAL (95) \\
\hline $3^{\prime}$ & $\begin{array}{l}C:(-\$ 4000: 80 \% ; \$ 0: 20 \%) \\
D:(-\$ 3000: 100 \%)\end{array}$ & $\begin{array}{l}82 \% \\
18 \%\end{array}$ & $\begin{array}{c}92 \% * \\
8 \%\end{array}$ \\
\hline PROBLEMA & PROSPECTO & BRASIL (97) & ORIGINAL (66) \\
\hline 4 & $\begin{array}{l}A:(\$ 4000: 20 \% ; \$ 0: 80 \%) \\
B:(\$ 3000: 25 \% ; \$ 0: 75 \%)\end{array}$ & $\begin{array}{l}57 \% \\
43 \% *\end{array}$ & $\begin{array}{l}65 \% * \\
35 \%\end{array}$ \\
\hline PROBLEMA & PROSPECTO & BRASIL (97) & ORIGINAL (66) \\
\hline $4^{\prime}$ & $\begin{array}{l}\text { C: }(-\$ 4000: 20 \% ; \$ 0: 80 \%) \\
D:(-\$ 3000: 25 \% ; \$ 0: 75 \%)\end{array}$ & $\begin{array}{l}37 \% \\
63 \%\end{array}$ & $\begin{array}{l}42 \% * \\
58 \%\end{array}$ \\
\hline PROBLEMA & PROSPECTO & BRASIL (97) & ORIGINAL (95) \\
\hline 7 & $\begin{array}{l}A:(\$ 6000: 45 \% ; \$ 0: 55 \%) \\
B:(\$ 3000: 90 \% ; \$ 0: 10 \%)\end{array}$ & $\begin{array}{l}23 \% \\
77 \% *\end{array}$ & $\begin{array}{l}14 \% \\
86 \% *\end{array}$ \\
\hline PROBLEMA & $\begin{array}{l}\text { PROSPECTO } \\
\end{array}$ & BRASIL (92) & ORIGINAL (95) \\
\hline $7^{\prime}$ & $\begin{array}{l}A:(-\$ 6000: 45 \% ; \$ 0: 55 \%) \\
B:(-\$ 3000: 90 \% ; \$ 0: 10 \%)\end{array}$ & $\begin{array}{l}75 \% * \\
25 \%\end{array}$ & $\begin{array}{c}92 \% * \\
8 \%\end{array}$ \\
\hline PROBLEMA & $\begin{array}{l}\text { PROSPECTO } \\
\end{array}$ & BRASIL (97) & ORIGINAL (66) \\
\hline 8 & $\begin{array}{l}\text { C: }(\$ 6000: 0,1 \% ; \$ 0: 99,9 \%) \\
\text { D: }(\$ 3000: 0,2 \% ; \$ 0: 99,8 \%)\end{array}$ & $\begin{array}{l}72 \% * \\
28 \%\end{array}$ & $\begin{array}{l}73 \% * \\
27 \%\end{array}$ \\
\hline PROBLEMA & PROSPECTO & BRASIL (92) & ORIGINAL (66) \\
\hline $8^{\prime}$ & $\begin{array}{l}\text { C: }(-\$ 6000: 0,1 \% ; \$ 0: 99,9 \%) \\
D:(-\$ 3000: 0,2 \% ; \$ 0: 99,8 \%)\end{array}$ & $\begin{array}{l}50 \% \\
50 \%\end{array}$ & $\begin{array}{l}30 \% \\
70 \% *\end{array}$ \\
\hline
\end{tabular}


sultados incertos. Porém, os dados empíricos não estabelecem que os resultados certos são sempre preferíveis. M ais ainda, a pesquisa coloca em questão uma das possíveis explicações para o efeito da certeza.

Por exemplo, Tobin (1958) estabelece que as escoIhas de al ternativas explicam-se pelo fato de as pessoas aval iarem os prospectos privilegiando valores esperados elevados e variâncias baixas. Assim, justifica-se a escolha do Prospecto B no Problema 3, pois a variância nula sobrepujaria o menor valor esperado. De modo similar, no Problema 4, escolhe-se o Prospecto A, pois a diferença de variância não é suficiente para compensar a diferença no valor esperado. Porém, quando se avalia o domínio das perdas, o argumento de Tobin não se torna razoável. No Problema 3', por exemplo, mesmo possuindo esperança maior e variância menor, o Prospecto C é preterido em relação ao Prospecto $D$, tanto na amostra original quanto na amostra brasileira. A partir desses resultados, Kahneman e T versky (1979) sugerem que a certeza aumenta a aversão a riscos, assim como aumenta o desejo de ganhos.

Focando a atenção na questão da aversão ao risco, uma das premissas usualmente associadas à teoria da utilidade esperada envolve a concavidade da função utilidade. Essa característica da função utilidade implica que os indivíduos são aversos ao risco e explica, por exemplo, por que há atratividade nos contratos de seguro em que o valor do prêmio pago pela apólice é superior ao valor esperado da possível perda. Porém, Fuchs (1976) sugere que a concavidade pode não ser observada em algumas situações. Por exemplo, os indivíduos violam a premissa de aversão ao risco quando preferem seguros com baixa franquia e cobertura limitada em detrimento de seguros com franquia maior e cobertura mais ampla.

Por meio do estabelecimento de um produto financeiro hipotético, chamado de seguro probabilístico de uma propriedade, Kahneman e Tversky (1979) ilustram a inconsistência dos indivíduos frente à hipótese de concavidade. Para ilustrar o que preten demos mostrar, considere-se o enunciado do Problema 9 descrito na Figura 5.

$\mathrm{Na}$ Tabela 4, o Prospecto $\mathrm{A}$ refere-se à não-aquisição do seguro probabilístico e o Prospecto $B$ refere-se à aquisição do seguro para a proteção de um ativo de valor W contra uma perda de valor $\mathrm{X}$. 0 seguro probabilístico confere apenas uma probabilidade $R$ de ressarcimento em caso de sinistro, e seu prêmio equivale a $R$ multiplicado pelo prêmio de equilíbrio de um seguro tradicional. $\mathrm{N}$ a descrição do produto, o prêmio $\mathrm{Y}$ de equilíbrio do seguro tradicional é o valor que faz com que o indivíduo fique indiferente entre realizar a proteção contra perdas e deixar a propriedade sem seguro. Sendo P a probabilidade de sinistro, os resultados na amostra brasileira também corroboram a inconsistência com a aversão ao risco, conforme se observa nos prospectos a seguir, onde o R utilizado foi de $50 \%$.

Os resultados sugerem que o seguro probabilístico é pouco atrativo para a maioria dos indivíduos. Assim, esse seguro viola a premissa de aversão ao risco,

Figura 5 - Enunciado do seguro probabilístico.

Problema 9. Suponha que você esteja considerando a possibilidade de segurar um imóvel contra algum dano, como por exemplo, incêndio ou roubo. Depois de examinar os riscos e o prêmio do seguro, você não encontra uma clara preferência entre a opção de adquirir o seguro e a opção de deixar o imóvel sem seguro. Porém, chama-Ihe a atenção que a seguradora está oferecendo um novo produto chamado Seguro Probabilístico.

Neste produto, você paga inicialmente metade do prêmio de um seguro tradicional. No caso de dano, existe uma probabilidade de $50 \%$ de que você pague a outra metade do prêmio e que a seguradora cubra todas as perdas. Existe também uma probabilidade de $50 \%$ de que, no caso de dano, você receba o valor já pago pelo prêmio e não seja ressarcido pelas perdas. Por exemplo, se 0 acidente ocorre em um dia ímpar, você paga a outra metade do prêmio e tem as perdas ressarcidas. Se 0 acidente ocorre em dia par, então a seguradora lhe devolve o prêmio pago e as perdas não são cobertas. Lembre-se de que o prêmio do seguro tradicional é tal que você avalia que o seguro praticamente equivale ao seu custo.

Sob estas circunstâncias, você prefere comprar o Seguro Probabilístico?
( ) Alternativa A
( ) Alternativa B
Sim
Não

Fonte: Adaptado de Kahneman e Tversky (1979). 
pois refl ete 0 fato de a atratividade de diminuir a probabilidade de perda de $\mathrm{P}$ para 50\%P ser menor do que a atratividade de diminuir a probabilidade de $50 \% \mathrm{P}$ para zero. Segundo Kahneman e Tversky (1979), o seguro probabilístico deveria ser superior ao seguro tradicional, pois se o indivíduo tem propensão a pagar um prêmio $Y$ para proteger-se contra uma perda $X$ que pode ocorrer com uma probabilidade $P$, então teria propensão a pagar um prêmio menor $R Y, 0<R<1$, para reduzir a probabilidade de perder $X$ de $P$ para ( 1 R)P. Ou seja, se o indivíduo fosse indiferente aos prospectos (W-X:P; W:1-P) e (W-Y:1), então preferiria 0 seguro probabilístico (W-X,(1-R)P; W-Y:RP; W-RY;1$P)$ ao seguro tradicional $(W-Y: 1)$. Porém, mais uma vez, as evidências empíricas têm mostrado que os indivíduos podem decidir de maneira inconsistente com a aversão ao risco, que constitui premissa fundamental em alguns model os financeiros.

Tversky (1972) tenta justificar alguns processos decisórios contrários à utilidade esperada argumen- tando que os indivíduos tendem a simplificar o processo de escolha entre alternativas, desconsiderando os componentes idênticos dos prospectos e sobreval orizando os componentes que diferenciam os prospectos. Kahneman e Tversky (1979) batizam esse fenômeno de efeito de isolamento, que eventualmente conduz a escolhas inconsistentes, pois os prospectos podem ser decompostos de diversas formas por meio de componentes comuns e de componentes distintos. Um exemplo desse efeito pode ser obtido comparando-se o Problema 4 com o Problema 10 descrito na Figura 6, no qual existem dois estágios. Os resultados empíricos podem ser avaliados na Tabela 5.

No Problema 10 existem $75 \%$ de chances de os prospectos terminarem no primeiro estágio e $25 \%$ de chances de continuarem para o segundo estágio. É fácil verificar que os prospectos dos Problemas 4 e 10 são equivalentes, porém apresentados por meio de diferentes componentes. Como no experimento de Kahneman e Tversky (1979), a simples formulação dos prospectos

Tabela 4 - Prospectos do seguro probabilístico.

\begin{tabular}{c|l|c|c}
\hline PROBLEMA & \multicolumn{1}{|c|}{ PROSPECTO } & BRASIL (96) & ORIGINAL (95) \\
\hline 9 & A: (W-X:(1-R)P; W-Y:RP; W-RY:1-P) & $28 \%$ & $20 \%$ \\
& B: (W-X:P; W:1-P) & $72 \% *$ & $80 \% *$ \\
\hline
\end{tabular}

Figura 6 - Enunciado do estudo da influência da estruturação dos prospectos nas escolhas.

Problema 10. Considere um jogo de dois estágios. No primeiro estágio, existe uma probabilidade de $75 \%$ de que o jogo termine sem que você ganhe nada e uma probabilidade de $25 \%$ de que se mova ao segundo estágio. Se você atingir o segundo estágio, você pode escolher entre as alternativas a seguir. Observe que a escolha deve ser feita antes do início do jogo.

( ) Alternativa A

$80 \%$ de chances de ganhar $\$ 4000$

$20 \%$ de chances de ganhar $\$ 0$
( ) Alternativa B

$100 \%$ de chances de ganhar $\$ 3000$

Fonte: Adaptado de Kahneman e Tversky (1979).

Tabela 5 - Influência da estruturação dos prospectos nas escolhas.

\begin{tabular}{|c|c|c|c|}
\hline PROBLEMA & PROSPECTO & BRASIL $(97)$ & ORIGINAL $(66)$ \\
\hline 4 & A: $(\$ 4000: 20 \% ; \$ 0: 80 \%)$ & $57 \%$ & $65 \% *$ \\
& B: $(\$ 3000: 25 \% ; \$ 0: 75 \%)$ & $43 \%$ & $35 \%$ \\
\hline PROBLEMA & \multicolumn{1}{|c|}{ PROSPECTO } & BRASIL (189) & ORIGINAL (141) \\
\hline 10 & A: $(\$ 0: 75 ;(\$ 4000: 80 \% ; \$ 0: 20 \%): 25 \%)$ & $22 \%$ & $22 \%$ \\
& B: $(\$ 0: 75 ;(\$ 3000: 100 \%): 25 \%$ & $78 \% *$ & $78 \% *$ \\
\hline
\end{tabular}


de uma maneira diferente faz com que os respondentes da amostra brasileira tenham comportamento oposto em relação a preferências por prospectos (veja a Tabela 6). 0 experimento mostra uma violação à suposição de que as decisões são determinadas somente pel as probabilidades dos possíveis resultados finais dos prospectos. Comparando-se os resultados do Problema $4 \mathrm{com}$ os do Problema 3, fortal ecem-se as evidências de que os indivíduos tendem a desconsiderar a informação comum aos dois prospectos. 0 foco da decisão no Problema 10 torna-se, portanto, equivalente aos prospectos do Problema 3, pois os indivíduos ignoram a informação sobre as probabilidades do primeiro estágio. Assim como os indivíduos preferem a alternativa B no Problema 3, preferem a alternativa B no Problema 10.

Os problemas 11 e 12, enunciados na Figura 7, corroboram um dos pilares de sustentação da teoria do prospecto, ou seja, os indivíduos conferem maior peso a alterações de riqueza do que a estados de riqueza.

A Tabela 6 sintetiza os resultados do experimento. No Problema 11, informou-se que, em adição ao que eventualmente já possui, o indivíduo recebe $\$ 1.000$. A partir desse ponto, o indivíduo deve escolher entre os Prospectos A e B. No Problema 12, o valor adicionado é \$2.000.

Quando analisados a partir dos resultados líquidos dos estados finais - considerando-se conjuntamente os val ores recebidos antes da decisão -, os Problemas 11 e 12 são idênticos, pois os Prospectos $A$ e $C$ equivalem a ( $\$ 2.000: 50 \% ; \$ 1.000: 50 \%)$ e os Prospectos B e $D$ equivalem a (\$1.500:100\%). Porém, independentemente da igual dade entre os problemas, os prospectos mais escolhidos são o B e o C. N a verdade, apesar de o Problema 12 ser igual ao Problema 11, somandose $\$ 1.000$ ao valor inicial e retirando-se $\$ 1.000$ dos prospectos, os indivíduos tendem a ignorar essa informação comum, focando a análise somente no ganho certo do Prospecto $B$ e na possibilidade de evitar a perda no Prospecto $C$. Essa investigação sugere que os indivíduos, ao escolherem alternativas, privilegiam alterações na riqueza em vez de valores totais de riqueza (Kahneman e Tversky, 1979)

Finalmente, outro estudo de Kahneman e Tversky (1981) mostra um resultado que desafia uma das premissas fundamentais da teoria da utilidade esperada,

Figura 7 - Enunciado do estudo da importância das alterações na riqueza em contraposição aos resultados finais.

Problema 11. Além dos recursos que você possui, você recebeu mais $\$ 1000$. Agora, você deve escolher entre as alternativas a seguir.

( ) Alternativa A

$50 \%$ de chances de ganhar $\$ 1000$

$50 \%$ de chances de ganhar $\$ 0$
( ) Alternativa B

$100 \%$ de chances de ganhar $\$ 500$

Problema 12. Além dos recursos que você possui, você recebeu mais $\$ 2000$. Agora, você deve escolher entre as alternativas a seguir.

( ) Alternativa A

$50 \%$ de chances de perder $\$ 1000$

$50 \%$ de chances de perder $\$ 0$
( ) Alternativa B

$100 \%$ de chances de perder $\$ 500$

Fonte: Adaptado de Kahneman e Tversky (1979).

Tabela 6 - Importância das alterações na riqueza em contraposição aos resultados finais.

\begin{tabular}{|c|l|c|c|}
\hline PROBLEMA & \multicolumn{1}{|c|}{ PROSPECTO } & BRASIL $(97)$ & ORIGINAL (70) \\
\hline 11 & A: $(\$ 1000: 50 \% ; \$ 0: 50 \%)$ & $30 \%$ & $16 \%$ \\
& B: $(\$ 500: 100 \%)$ & $70 \% *$ & $84 \% *$ \\
\hline PROBLEMA & \multicolumn{1}{|c|}{ PROSPECTO } & BRASIL (92) & ORIGINAL (78) \\
\hline 12 & C: $(-\$ 1000: 50 \% ; \$ 0: 50 \%)$ & $65 \% *$ & $69 \% *$ \\
& D: $(-\$ 500: 100 \%)$ & $35 \%$ & $31 \%$ \\
\hline
\end{tabular}


na qual a decisão deve ser invariável em relação a uma situação de decisão, independentemente da sua estruturação. 0 enunciado da Figura 8 resume duas formas diferentes de apresentar os mesmos prospectos.

Os resultados descritos na Tabela 7 mostram a negação do princípio da invariância: representações distintas do mesmo problema de escolha devem produzir as mesmas referências. $\mathrm{Na}$ segunda estrutura, os resultados são apresentados em termos positivos (vidas salvas), e a maioria dos respondentes apresenta aversão ao risco (a perspectiva de salvar 200 vidas com absoluta certeza é mais atraente do que um prospecto que embute risco com o mesmo valor esperado). Em contrapartida, quando os resultados são apresentados em termos negativos na primeira estrutura, a morte certa de 400 pessoas é menos aceitável do que uma probabilidade de $2 / 3$ de que 600 pessoas morrerão.

\section{COMENTÁRIOS FINAIS}

Por fundamentar importantes aspectos da hipótese de mercados eficientes, a teoria da utilidade esperada possibilita que se construam diversos modelos financeiros. As contribuições da hipótese de mercados eficientes são inúmeras, e diversas técnicas de avaliação financeira são utilizadas tendo como premissa a busca da maximização da utilidade.

Porém, pesquisas em psicologia têm encontrado diversos indícios de que os seres humanos tendem consistentemente a tomar decisões que violam suposições da teoria da utilidade esperada. N esse contexto, a teoria do prospecto tem-se demonstrado extremamente promissora para a modelagem do comportamento decisório dos indivíduos. Tendo origens nos trabal hos de Kahneman e Tversky (1979, 1981 e 1982), as finan-

Figura 8 - Enunciado do estudo de falhas na invariância.

Problema 13. Suponha que o Brasil esteja se preparando contra uma doença asiática incomum. Estima-se que a doença irá matar 600 pessoas. Dois programas alternativos de combate à doença são propostos. Assuma que as estimativas científicas exatas das conseqüências dos programas sejam dadas a seguir:

\section{Estrutura 1}

Se o Programa A for adotado, 400 pessoas morrerão;

Se o Programa B for adotado, existe uma probabilidade de $1 / 3$ de que ninguém morra e uma probabilidade de $2 / 3$ de que todas as 600 pessoas morram.

De qual programa você é a favor?
( ) Programa A
( ) Programa B

\section{Estrutura 2}

Se o Programa A' for adotado, 200 pessoas serão salvas;

Se o Programa B' for adotado, existe uma probabilidade de $1 / 3$ de que todas sejam salvas e uma probabilidade de $2 / 3$ de que nenhuma das 600 pessoas seja salva.

De qual programa você é a favor?
( ) Programa A'
( ) Programa B'

Fonte: Adaptado de Kahneman e Tversky (1979).

Tabela 7 - Estudo de falhas de invariância.

\begin{tabular}{|c|c|c|c|}
\hline PROBLEMA & PROGRAMA & BRASIL (93) & ORIGINAL (152) \\
\hline 13 & A & $30 \%$ & $22 \%$ \\
& B & $70 \% *$ & $78 \% *$ \\
\hline & A $^{\prime}$ & $71 \% *$ & $72 \% *$ \\
\hline & B' $^{\prime}$ & $29 \%$ & $28 \%$ \\
\hline
\end{tabular}


ças comportamentais representam um importante campo de investigação, por possibilitarem que atitudes não racionais dos investidores possam ser incorporadas nos processos de tomada de decisão entre alternativas financeiras. Dessa forma, as finanças comportamentais constituem um avanço teórico que busca diminuir 0 distanciamento entre a prática da tomada de decisão dos agentes econômicos e os model os tradicional mente aceitos baseados na moderna teoria de finanças.

Adicionalmente, por constituírem uma linha de pesquisa promissora, que vem obtendo importantes resultados tanto acadêmicos quanto práticos, as finanças comportamentais estão se consolidando como uma teoria que permite representação, estimação e interpretação al ternativas do comportamento de variáveis financeiras. Além de diversas pesquisas já terem sido desenvolvidas no meio acadêmico, os praticantes de finanças têm utilizado conceitos de finanças comportamentais para orientar seus investimentos. De acordo com Burr (1997), pelo menos 72 bilhões de dólares já são investidos utilizando-se descobertas e técnicas que levam em consideração os aspectos psicológicos dos investidores. Por exemplo, diversos fundos investem em estratégias de momento ou em estratégias contrárias, que supõem e predominância de comportamentos baseados em conservadorismo ou em excesso de confiança. De acordo com as finanças comportamentais, conservadorismo ou excesso de confiança podem conduzir tanto à sub-reação como à sobrereação do mercado. Dessa forma, a estratégia de momento se baseia na compra de ativos com as melhores rentabilidades passadas e na venda de ativos com as piores rentabilidades passadas. Em contrapartida, a estratégia contrária se fundamenta na compra de ativos com as piores rentabilidades passadas e na venda de ativo com as melhores rentabilidades passadas.

Neste artigo, por meio da descrição de estudos em psicologia, apresentaram-se al guns aspectos comportamentais que podem conduzir a atitudes não racionais, do ponto de vista da teoria financei ra tradicional. Devese enfatizar que os prospectos apresentados sugerem que os indivíduos percebem as escol has, financeiras ou não, a partir de percepções diferentes do que a teoria moderna de finanças estabelece. Em particular, o risco avaliado pelos indivíduos parece depender do efeito da certeza, do efeito da refl exão e da forma de estruturação das al ternativas, em contraposição ao desvio padrão de retornos, conforme advoga a teoria moderna de finanças. Por exemplo, a busca de ganhos certos ou a aversão a perdas certas pode ter mais impacto nas escolhas do que o próprio risco dos investimentos. Assim, esses comportamentos não racionais do ponto de vista da teoria moderna de finanças podem eventual mente explicar a existência de anomalias. Exemplificando, a forma de estruturação de al ternativas pode explicar o enigma dos dividendos, no qual os investidores preferem dividendos, apesar de uma taxa de tributação maior em comparação ao ganho de capital.

A teoria de prospecto também foi discutida caracterizando as funções de valor e de pesos de decisão aos quais os indivíduos tendem a recorrer no processo decisório frente a alternativas financeiras. Finalmente, replicou-se, no contexto brasileiro, a investigação empírica do artigo seminal de Kahneman e Tversky (1979) que aborda a teoria de prospecto e constitui a base de finanças comportamentais. Conforme sugerem os resultados denotados nas tabelas, a amostra brasileira indica a existência dos mesmos vieses encontrados pela amostra original de Kahneman e T versky. Não foram encontradas diferenças significativas entre os resultados da amostra brasileira e os da original, o que fortalece as evidências de que aspectos comportamentais podem influenciar as escolhas dos indivíduos. Em termos de significância estatística, destaca-se que 0 efeito da certeza foi menos acentuado na amostra brasileira. Identificam-se situações em que a diferença percentual de escolhas entre prospectos relacionados ao efeito da certeza não chegou a ser significativa ao nível de $1 \%$. Porém, em linhas gerais, dadas as semeIhanças com os resultados da pesquisa de Kahneman e Tversky, os resultados da avaliação empírica desta pesquisa sugerem que os aspectos comportamentais na tomada de decisão mantêm-se ao longo do tempo e são pouco influenciados por possíveis vieses culturais. Destaca-se que não há ainda uma teoria consolidada e consagrada sobre finanças comportamentais, porém muitas pesquisas e estudos estão sendo desenvolvidos visando explicar ou refutar paradoxos em relação à teoria moderna de finanças. 0 comportamento ligado a decisões financei ras constitui hoje interessante campo de pesquisa na área de finanças, incorporando modelagem matemática e pesquisa empírica, inclusive aspectos de psicologia.

\section{REFERÊNCIAS BIBLIOGRÁFICAS}

ALLAIS, M. Le comportement de l'homme rationnel devant le risque: critique des postulats et axiomes de l'école Américaine. Econometrica, v. 21, p. 503-546, 1953. 
BARBERIS, N.; HUANG, M. Mental accounting, loss aversion, and individual stock returns. Journal of Finance, v. 56, n. 4, p. 1247-1292, 2001.

BENARTZI, S.; THALER, R. Myopic loss aversion and the equity premium puzzle. Quarterly Journal of Economics, v. 110, n. 1, p. 73-92, 1995.

BURR, B. Behavioral finance: too interesting. Pensions and Investments, $v$. 18, p. 8, 1997.

DeBONDT, W.; THALER, R. Does the market overreact?. Journal of Finance, V. 40, n. 3, p. 793-805, 1985.

EDWARDS, W. The theory of decision making. Psychological Bulletin, $v$. 51, p. 380-417, 1954.

FAMA, E. Efficient capital markets: a review of theory and empirical work. Journal of Finance, v. 25, p. 383-417, 1970.

FESTINGER, L.; CARLSMITH, J. M. Cognitive consequences of forced compliance. Journal of A bnormal and Social Psychology, v. 58, p. 203-210, 1959.

FESTINGER. L. A Theory of Cognitive Dissonance. Evanston, IL: Row, Peterson, 1957.

FUCHS, V. From Bismarck to Woodcock: The "irrational" pursuit of national health insurance. Journal of Law and Economics, v. 19, p. 347-359, 1976.

JENSEN, M. Some anomal ous evidence regarding market efficiency. Journal of Financial Economics, v. 6, p. 95-101. 1978.

KAHNEMAN, D.; TVERSKY, A. The psychology of preferences. Scientific American, v. 146, p. 160-173, 1982.

KAHNEMAN, D.; TVERSKY, A. Prospect theory: an analysis of decision under risk. Econometrica, v. 47, n. 2, p. 263-291, 1979.
KAHNEMAN, D.; TVERSKY, A. The framing of decisions and psychology of choice. Science, v. 211, p. 453-458, 1981.

KING, M.; LEAPE, J. Wealth and portfolio composition: theory and evidence. Journal of Public Economics, v. 69, p. 155-193, 1998.

LOOMES, G.; SUGDEN, R. Regret theory: an alternative theory of rational choice under uncertainty. Economic Journal, v. 92, p. 805-824, 1982.

ODEAN, T. Are investors reluctant to realize their losses? Working paper. Graduate School of Management, University of California: Davis, 1998.

PROTHRO, J. W.; GRIGG, C. M. Fundamental principles of democracy: bases of agreement and disagreement. Journal of Politics, v. 22, p. 276-294, 1960.

SHEFRIN, H. M. Beyond Greed and Fear. Harvard Business School Press, 2000.

SHLEIFER, A. Inefficient M arkets: An Introduction to Behavioral Finance. N ew York. Oxford University Press, 2000.

THALER, R. H. The end of behavioral finance. Financial Analysts Journal, p. 12-17, 1999.

TVERSKY, A. Elimination by aspects: a theory of choice. Psychological Review, v. 79, p. 281-299, 1972.

TOBIN, J. Liquidity preference as behavior toward risk. Review of Economic Studies, v. 25, p. 65-86, 1958.

WICKER, A. W. Attitudes versus actions: the relationship of verbal and overt behavioral responses to attitude objects. Journal of Social Issues, v. 25, p. 41-78, 1969.

\section{Artigo recebido em 27.05.2004. Aprovado em 14.09.2005.}

\section{Herbert Kimura}

Professor da Universidade Presbiteriana Mackenzie. Doutor em Administração pela USP.

Interesses de pesquisa nas áreas de derivativos, criação de valor, finanças comportamentais e finan-

ças corporativas.

E-mail: hkimura@mackenzie.com.br

Endereço: Rua da Consolação, 896, 70 andar, sala 76, Consolação, São Paulo - SP, 01302-907.

\section{Leonardo Fernando C ruz Basso}

Professor da Universidade Presbiteriana Mackenzie. Doutor em Economia pela New School for Social Research, New York.

Interesses de pesquisa nas áreas de criação de valor, finanças comportamentais e finanças corporativas.

E-mail: leonardobasso@mackenzie.com.br

Endereço: Rua da Consolação, 896, 7 a andar, sala 76, Consolação, São Paulo - SP, 01302-907.

\section{Elizabeth Krauter}

Doutoranda em Administração na FEA-USP.

Interesses de pesquisa nas áreas de criação de valor, finanças comportamentais e finanças corporativas.

E-mail: ekrauter@usp.br

Endereço: Rua M arina Crespi, 195, apto. 2203, M ooca, São Paulo - SP, 03112-090.

58 - ORAE - VOL. 46 - No1 